\title{
Adubação da bananeira 'Prata Anã' com diferentes doses e fontes de nitrogênio
}

\author{
José T. A. da Silva ${ }^{1}$, Rosimeire D. Pereira ${ }^{2} \&$ Maria G. V. Rodrigues ${ }^{1}$
}

\section{RESU M O}

Objetivou-se, com este trabalho, verificar qual fonte de N (sulfato de amônio, nitrato de amônio, nitrato de cálcio e uréia) é apropriada à bananeira e determinar a dose para se obter a máxima eficiência física e econômica. Os experimentos foram instalados na região semiárida do norte de Minas Gerais em Latossolo Vermelho argiloso e Latossolo Vermelho Amarelo textura média. 0 delineamento experimental foi de blocos casualizados com 20 tratamentos e quatro repetições. O s tratamentos foram dispostos em arranjo fatorial $4 \times 5$ correspondendo a quatro fontes de $\mathrm{N}$ (sulfato de amônio, nitrato de amônio, nitrato de cálcio e ureia) e a cinco doses de $\mathrm{N}\left(0,100,200,400\right.$ e $\left.800 \mathrm{~kg} \mathrm{ha}^{-1} \mathrm{ano}^{-1}\right)$. $\mathrm{O} \mathrm{N}$ el evou a produção no 1 o ciclo da bananeira cultivada no Latossolo Vermelho Amarelo cujas doses de $\mathrm{N}$, visando obter a máxima eficiência física, foram 521, 471, 410 e $424 \mathrm{~kg} \mathrm{ha}^{-1}$ e, para se obter a máxima eficiência econômica, foram 105, 204, 260 e $5 \mathrm{~kg} \mathrm{ha}^{-1}$ para o sulfato de amônio, nitrato de amônio, ureia e nitrato de cálcio, respectivamente, sendo a ureia a fonte de $\mathrm{N}$ mais eficiente. Já nos $2 \circ$ e 30 ciclos o $\mathrm{N}$ reduziu a produção. No Latossolo Vermel ho não houve efeitos do $\mathrm{N}$ sobre as variáveis de desenvolvimento vegetativo e de produção, nos 10 e 20 ciclos da bananeira.

Palavras-chave: nutrição, Musa sp., Latossolo

\section{Fertilization of the banana 'Prata Anã' with different rates and sources of nitrogen}

\begin{abstract}
The objective of this study was to verify appropiate $\mathrm{N}$ sources (ammonium sulfate, ammonium nitrate, calcium nitrate and urea) for banana and to determine the application rate for maximum physical and economic efficiency. The experiments were conducted in northern semiarid region of Minas Gerais in Red Latosol and Red-Yellow Latosol. The experimental design was in randomized blocks with 20 treatments and four repetitions. The treatments were arranged in $(4 \times 5)$ factorial, being four $\mathrm{N}$ sources (ammonium sulfate, ammonium nitrate, calcium nitrate and urea) and five $\mathrm{N}$ rates $\left(0,100,200,400\right.$ and $800 \mathrm{~kg} \mathrm{ha}^{-1}$ year ${ }^{-1}$ ). The $\mathrm{N}$ increased production in the $1^{\text {st }}$ cycle of banana grown in the Red-Yellow Latosol, where $\mathrm{N}$ rates for maximum physical efficiency were $521,471,410,424 \mathrm{~kg} \mathrm{ha}^{-1}$ and to achieve maximum economic efficiency were 105, 204, 260 and $5 \mathrm{~kg} \mathrm{ha}^{-1}$ for ammonium sulfate, ammonium nitrate, urea and calcium nitrate, respectively, with urea being the most efficient source of nitrogen. In the $2^{\text {nd }}$ and $3^{\text {rd }}$ cycles $\mathrm{N}$ reduced production. In the Red Latosol, no effects of $\mathrm{N}$ on the variables of plant growth and production were observed in the $1^{\text {st }}$ and $2^{\text {nd }}$ cycles of banana.
\end{abstract}

Key words: nutrition, Musa sp., Latosol

\footnotetext{
${ }^{1}$ Empresa de Pesquisa Agropecuária de M inas Gerais, Unidade Regional do Norte de Minas, C. P. 12, CEP 39525-000, N ova Porteirinha, M G. Fone: (38) 3834 1760. E-mail: josetadeu@epamig.br; magevr@hotmail.com

${ }^{2}$ Bolsista de iniciação científica da FAPEM IG - Empresa de Pesquisa Agropecuária de Minas Gerais U nidade Regional do N orte de M inas, C. P. 12, CEP 39525-000, N ova Porteirinha, M G. E-mail: rosimeire.dantas@yahoo.com.br
} 


\section{INTRODUÇÃO}

As plantas são capazes de absorver o nitrogênio $(\mathrm{N})$ do meio em diferentes formas: $\mathrm{N}_{2}$ no caso das leguminosas pela fixação biológica e nas formas $\mathrm{NH}_{4}^{+}$e $\mathrm{NO}_{3}^{-}$, esta última predominante em condições naturais devido ao processo de nitrificação.

$\mathrm{O} \mathrm{N}$ é facilmente redistribuído nas plantas via floema, na forma de aminoácidos. Quando o suprimento de $\mathrm{N}$ pelo meio é suficiente, o $\mathrm{N}$ das folhas velhas é mobilizado para os órgãos e folhas mais novas. A carência de nitrogênio em bananeiras reduz o número de folhas, aumenta o número de dias para emissão de uma folha e ocorre clorose generalizada das folhas, além da formação de cachos raquíticos e menor número de pencas (Silva et al., 1999).

Cerca de $90 \%$ do $\mathrm{N}$ da planta se encontram em forma orgânica e é assim que ele desempenha suas funções como componente estrutural de macromoléculas e constituinte de enzimas. O N exerce também importante papel no processo da fotossíntese visto que é indispensável para a formação da molécula de clorofila. $\mathrm{O} \mathrm{N}$ faz parte de moléculas de aminoácidos e proteínas além de ser constituinte de bases nitrogenadas e ácidos nucléicos participando, ainda, de processos como absorção iônica, fotossíntese, respiração, multiplicação e diferenciação celular.

A bananeira é uma planta exigente em nutrientes não só por produzir grande massa vegetativa mas também por apresentar elevadas quantidades de elementos absorvidos pela planta e exportados pelos frutos (Silva et al., 1999). O N é, depois do potássio (K) o nutriente mais absorvido pela bananeira. Este nutriente é muito importante na fase de desenvolvimento vegetativo das plantas até o início da emissão do cacho (Silva et al., 2003).

Borges et al. (2002a) recomendam $200 \mathrm{~kg} \mathrm{ha}^{-1}$ de $\mathrm{N}$ na fase de formação e de 160 a $400 \mathrm{~kg} \mathrm{ha}^{-1}$ ano $^{-1}$ na fase de produção da bananeira, de acordo com a produtividade esperada. As doses recomendadas para as bananeiras cultivadas no norte de Minas Gerais variam de 100 a $140 \mathrm{~kg} \mathrm{ha}^{-1} \mathrm{ano}^{-1}$ dependendo da produtividade esperada (Silva \& Borges, 2008).

Em seu trabalho, Pinto et al. (2005) observaram, estudando os efeitos da aplicação de quatro doses de $\mathrm{N}(0,150,300$ e 600 $\left.\mathrm{kg} \mathrm{ha}^{-1}\right)$ no $1^{\circ}$ ciclo da bananeira 'Pacovan', efeito quadrático do $\mathrm{N}$ sobre a produção da bananeira, obtendo a produção máxima com a aplicação de $340 \mathrm{~kg}$ de $\mathrm{N} \mathrm{ha}^{-1}$. De acordo com os autores, a resposta da bananeira à aplicação de $\mathrm{N}$ ocorreu em virtude do solo da área experimental ser arenoso e com baixo teor de matéria orgânica $\left(4,1 \mathrm{~g} \mathrm{dm}^{-3}\right)$. Já Brasil et al. (2000) verificaram resposta linear da bananeira 'Pioneira' no $2^{\circ}$ ciclo de produção e não observaram efeitos da aplicação do $\mathrm{N}$ sobre a produção nos $1^{\circ}$ e $3^{\circ}$ ciclos.

A aplicação de $\mathrm{N}$ em solo com médio a alto teor de matéria orgânica pode não proporcionar efeitos ou até mesmo reduzir a produção da bananeira pelo excesso de $\mathrm{N}$, provocando desequilíbrio nutricional na bananeira. Portanto, deve-se ter bastante cuidado no momento de recomendar $\mathrm{N}$ para essa cultura de vez que tanto sua falta como o excesso reduzem a produção. Borges et al. (2002b) não obtiveram, avaliando doses de $\mathrm{N}$ fornecidas à bananeira 'Terra', efeitos significativos na produção haja vista que o solo onde foi conduzido o experimento continha $43 \mathrm{~g} \mathrm{dm}^{-3}$ de matéria orgânica e $1,8 \mathrm{~g} \mathrm{dm}^{-3}$ de $\mathrm{N}$ total; além disto foram aplicados $10 \mathrm{~L}$ de esterco de curral em todos os tratamentos o que, provavelmente, forneceu parte do N requerido pela bananeira. Silva et al. (2003) verificaram que a aplicação de doses crescentes de $\mathrm{N}$ promoveu queda na produção da bananeira 'Prata Anã', nos $2^{\circ}$ e $3^{\circ}$ ciclos, enquanto Maia et al. (2003) não verificaram efeitos significativos da aplicação de $\mathrm{N}$ no solo com teor de matéria orgânica de 24 $\mathrm{g} \mathrm{dm}^{-3}$ sobre a produção da bananeira 'Prata Anã'. Resultado semelhante foi encontrado por Santos et al. (2009).

De acordo com Silva \& Borges (2008) as fontes de N mais utilizadas na bananeira são ureia e sulfato de amônio; entretanto, o nitrato de amônio também tem sido utilizado, embora em menor proporção, como fonte de N.

O sulfato de amônio é a fonte que mais acidifica o solo, é corrosivo, apresenta alto índice salino, menor solubilidade em água entre as fontes nitrogenadas além de baixo conteúdo de N (20\%); a vantagem deste fertilizante é apresentar, em sua fórmula, $24 \%$ de enxofre; ressalta-se que existem situações específicas nas quais é necessário reduzir o $\mathrm{pH}$ ou pelo menos tentar evitar que se mantenha subindo, como é comumente observado em bananais irrigados com água subterrânea rica em carbonatos, no norte de Minas, cujo uso pode ser indicado.

A ureia apresenta as vantagens de possuir alto teor de $\mathrm{N}$ (44\%), alta solubilidade e menor preço efetivo; suas desvantagens são: apresentar alto potencial em acidificar o solo, apesar de inferior ao sulfato de amônio, possuir apenas $\mathrm{N}$ em sua composição, ter alto poder de volatilização e ser higroscópica.

$\mathrm{O}$ nitrato de amônio é outra fonte de $\mathrm{N}$ utilizada na bananicultura; apresenta $33 \%$ de N, dos quais $50 \%$ na forma nítrica e $50 \%$ na forma amoniacal, com a vantagem de apresentar quantidades iguais de amônio e nitrato embora apresente, também, elevada higroscopicidade, alto índice salino e potencial de acidificação do solo.

O nitrato de cálcio é formado pela mistura de calcário calcítico ou dolomítico moído com nitrato de amônio. O nitrato de cálcio é um excelente adubo nitrogenado do ponto de vista químico, pois apresenta $27 \%$ de $\mathrm{N}$, sendo metade na forma amoniacal e a outra metade na forma nítrica, semelhante ao nitrato de amônio; apresenta, também, carbonatos de Ca e $\mathrm{Mg}$, o que proporciona, a este adubo, baixo potencial de acidificação do solo. O nitrato de cálcio tem, como principal desvantagem, elevado custo em relação às outras fontes mencionadas.

Objetivou-se, com este trabalho, verificar qual fonte de $\mathrm{N}$ (sulfato de amônio, nitrato de amônio, nitrato de cálcio e ureia) é apropriada para a bananeira e, ainda, determinar a dose de $\mathrm{N}$ para se obter a máxima eficiência física e econômica na bananeira 'Prata Anã'.

\section{Material E MÉtodos}

Os experimentos foram instalados na região semiárida de Minas Gerais, município que apresenta latitude de $15^{\circ} 48^{\prime} 09^{\prime \prime}$ sul, longitude $43^{\circ} 18^{\prime \prime} 32^{\prime}$ oeste, altitude de $533 \mathrm{~m}$ e médias anuais de precipitação de $900 \mathrm{~mm}$, temperatura de $25^{\circ} \mathrm{C}$ e umidade relativa do ar de $56 \%$. 
Tabela 1. Resultado das análises químicas e granulométrica do Latossolo Vermelho (LV) e Latossolo Vermelho amarelo (LVA), 2011

\begin{tabular}{|c|c|c|c|c|c|c|c|c|c|c|}
\hline \multirow{2}{*}{ Solo } & \multirow{2}{*}{ pH } & ${ }^{1} \mathbf{P}$ & ${ }^{1} K$ & Al & $\mathrm{Ca}$ & $\mathrm{Mg}$ & \multirow{2}{*}{$\begin{array}{c}{ }^{2} \mathrm{MO} \\
\mathrm{g} \mathrm{dm}{ }^{-3}\end{array}$} & Argila & Silte & Areia \\
\hline & & & & & $\left.10\right|_{c} d$ & & & \multicolumn{3}{|c|}{$\mathrm{g} \mathrm{kg}^{-1}$} \\
\hline LV & 6,1 & 3,3 & 128 & 0 & 6,5 & 1,6 & 24 & 500 & 290 & 210 \\
\hline LVA & 5,2 & 2,4 & 87 & 0 & 2,0 & 0,4 & 11 & 250 & 150 & 600 \\
\hline
\end{tabular}

${ }^{1}$ Extrator Melich-1; ${ }^{2}$ Matéria orgânica

Dois experimentos, constituídos de tratamentos semelhantes, foram instalados em solos classificados como Latossolo Vermelho eutrófico (LV) textura argilosa e Latossolo Vermelho amarelo distrófico (LVA) textura média (EMBRAPA, 2006). Foram utilizadas mudas de bananeira 'Prata Anã,' obtidas de cultura de tecido, plantadas em covas de $0,10 \times 0,10 \mathrm{~m}$, espaçadas 2,5 m, abertas dentro de sulcos espaçados de 3,0 m.

Antes da adubação e do plantio amostras dos dois solos foram coletadas na profundidade de 0 a 0,20 m e determinados o $\mathrm{pH}$ em água, teores de $\mathrm{P}, \mathrm{K}, \mathrm{Al}, \mathrm{Ca}, \mathrm{Mg}$, matéria orgânica e a granulometria. As variáveis químicas e a granulometria dos solos onde foram conduzidos os dois experimentos, estão na Tabela 1.

Nos dois experimentos o delineamento foi de blocos casualizado, com 20 tratamentos e quatro repetições; os tratamentos foram dispostos em arranjo fatorial $4 \times 5$, correspondendo a quatro fontes de $\mathrm{N}$ (sulfato de amônio, nitrato de amônio, nitrato de cálcio e ureia) e cinco doses de $\mathrm{N}(0,100,200,400$ e 800 $\mathrm{kg} \mathrm{ha}^{-1}$ ano $^{-1}$ ) baseadas em Silva et al. (2003). As adubações nitrogenadas foram parceladas mensalmente e iniciadas 30 dias após o plantio; as parcelas dos experimentos foram constituídas de 24 famílias de bananeiras, com oito famílias na área útil.

As plantas foram conduzidas com a formação de "famílias" compostas da planta mãe ( $1^{\circ}$ ciclo), planta filha ( $2^{\circ}$ ciclo $)$ e planta neta $\left(3^{\circ}\right.$ ciclo). Os experimentos foram irrigados por microaspersão, com lâmina de água calculada com base na evaporação do tanque classe A.

No preparo da área fez-se a calagem, antes do plantio, visando elevar a saturação por bases do solo a 70\%, necessária apenas no LVA, utilizando-se o calcário dolomítico, com PRNT de $100 \%$; as adubações de plantio, de crescimento e de frutificação das bananeiras foram realizadas com base nas análises de solo e de folhas (Silva et al., 1999). Nessas adubações foram aplicados $500 \mathrm{~g}$ de superfosfato simples na cova de plantio e $200 \mathrm{~g}$ a cada seis meses, $80 \mathrm{~g}$ de cloreto de potássio por planta, mensalmente, $50 \mathrm{~g}$ de sulfato de magnésio a cada três meses, $50 \mathrm{~g}$ de sulfato de zinco e $10 \mathrm{~g}$ de ácido bórico a cada quatro meses; esses adubos foram aplicados manualmente, em semicírculo, a 0,40 m distante das plantas.

No início da emissão do cacho coletou-se a $3^{\text {a }}$ folha a partir doápice, de onde se retirou 0,10 m do centro do limbo, eliminandose a nervura central. $\mathrm{O}$ material colhido foi colocado para secar em estufa com circulação forçada de ar, a $70^{\circ} \mathrm{C}$, durante $72 \mathrm{~h}$ cujo material, após secagem e moído, foi analisado e os teores de N, P, K, S, Ca e Mg determinados (Malavolta et al., 1997).

Os experimentos realizados nos LVA e LV foram executados durante três e dois ciclos de produção, respectivamente; no experimento localizado no LV ocorreu alta incidência do Maldo-Panamá, doença causada pelo fungo Fusarium oxisporium F. sp Cubense, que dizimou $90 \%$ das plantas e impossibilitou a colheita do $3^{\circ}$ ciclo.
As variáveis de desenvolvimento vegetativo (altura, diâmetro do pseudocaule a $0,30 \mathrm{~m}$ da superfície do solo e o número de folhas vivas) foram avaliadas no início da emissão do cacho de cada planta enquanto as variáveis de produção (produção da bananeira, número de pencas por cacho, comprimento e diâmetro do fruto mediano da $2^{\mathrm{a}}$ penca de cada cacho) foram obtidas na colheita do cacho de cada planta da parcela útil; os dados obtidos foram submetidos às análises de variância, teste $\mathrm{F}$ e ajustes de regressão, com nível de significância de até $5 \%$ de probabilidade.

Para obter a máxima eficiência física (MEF) igualou-se a zero a primeira derivada das regressões quadráticas utilizandose as quatro fontes de N, conforme a Eq. 1.

$$
\frac{d \hat{y}}{d x}=0
$$

em que:

dy/dx - primeira derivada das regressões quadráticas ajustadas entre a produção de banana em função das doses de N

Visando à máxima eficiência econômica (MEE) igualou-se a primeira derivada das regressões quadráticas à relação de preços do $\mathrm{N}$ e da banana, conforme Eq. 2.

$$
\frac{d \hat{y}}{d x}=\frac{P x}{P y}
$$

em que:

Px - preço do kg de $\mathrm{N}$ contido no sulfato de amônio, nitrato de amônio, uréia e nitrato de cálcio

Py - preço do kg de banana

Para determinar a MEE realizou-se a tomada de preços em julho de 2012, no comércio do norte de Minas Gerais, quando então os valores encontrados para o $\mathrm{kg}$ da ureia, nitrato de amônio, sulfato de amônio e nitrato de cálcio, foram $\mathrm{R} \$ 1,80$; 1,$90 ; 1,40$ e 1,96, respectivamente e o valor do kg de N contido em cada fonte foi $\mathrm{R} \$ 4,32 ; 5,80 ; 7,00$ e 12,64, respectivamente.

Preço do $\mathrm{kg}$ de banana $=\mathrm{R} \$ 1,00$ (preço referente à média de preços do ano de 2011, informado pela Associação Central dos Fruticultores do Norte de Minas - Abanorte).

\section{Resultados e Discussão}

No LVA o N não influenciou as variáveis de crescimento vegetativo, o número de pencas/cacho, comprimento nem o 
diâmetro do fruto, nos $1^{\circ}, 2^{\circ}$ e $3^{\circ}$ ciclos de produção; entretanto, elevou a produção de banana de forma quadrática no $1^{\circ}$ ciclo (Figura 1A). As doses de $\mathrm{N}$ para obter a máxima eficiência física (MEF) foram 521, 471, 410 e $424 \mathrm{~kg} \mathrm{ha}^{-1} \mathrm{ano}^{-1}$, para o sulfato de amônio, nitrato de amônio, ureia e nitrato de cálcio, respectivamente.

Um dos principais motivos para o $\mathrm{N}$ ter proporcionado aumento de produção no $1^{\circ}$ ciclo da bananeira cultivada no LVA, está relacionado ao baixo teor de matéria orgânica presente neste solo classificado, por Alvarez et al. (1999) como baixo (Tabela 1). Brasil et al. (2000) observaram que a aplicação de N no solo elevou linearmente o peso da massa do cacho no $2^{\circ}$

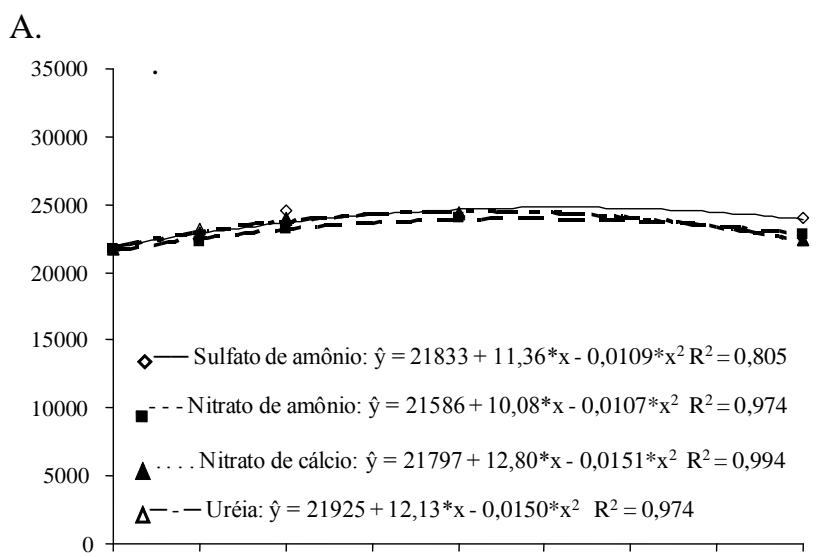

B.

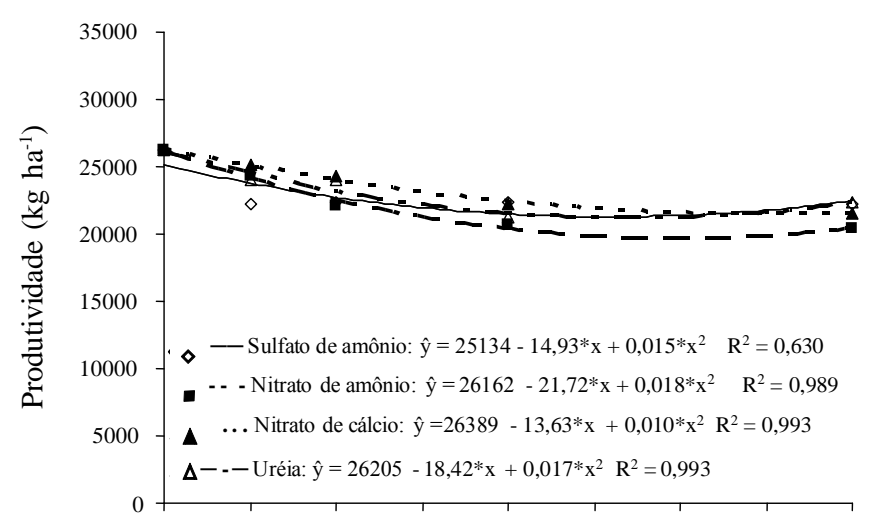

C.

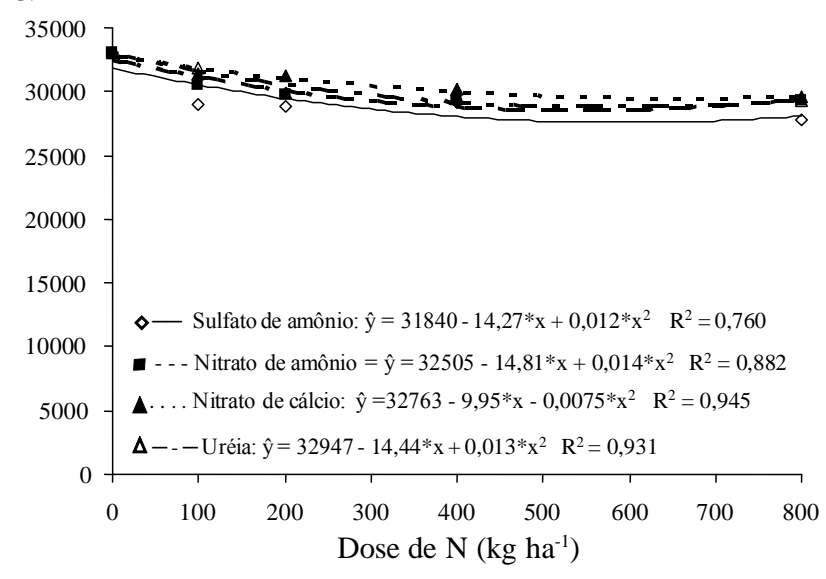

* significante a 0,05 de probabilidade

Figura 1. Produção da bananeira 'Prata Anã' nos $1^{\circ}(A)$, 2 (B) e 30 (C) ciclos em função de doses de $\mathrm{N}$ aplicadas no LVA com diferentes fontes ciclo da bananeira 'Pioneira', resultado este relacionado ao baixo teor de matéria orgânica $\left(14 \mathrm{~g} \mathrm{dm}^{-3}\right)$ presente no solo.

As doses estimadas de $\mathrm{N}$ no $1^{\circ}$ ciclo de produção para se obter a máxima eficiência econômica (MEE) foram 105, 204, 260 e $5 \mathrm{~kg} \mathrm{ha}^{-1}$ utilizando-se, como fontes, o sulfato de amônio, nitrato de amônio, ureia e nitrato de cálcio, respectivamente; essas doses de $\mathrm{N}$ elevaram a produção de banana em 4,9; 7,5; 9,8 e $0,3 \%$ em relação à testemunha; desta forma, a ureia foi mais eficiente em relação às outras fontes. Para uma produtividade esperada de 20 a $30 \mathrm{t} \mathrm{ha}^{-1} \mathrm{ano}^{-1}$, Silva \& Borges (2008) recomendam $100 \mathrm{~kg} \mathrm{ha}^{-1}$ de N. Entretanto, esses autores não consideraram o teor de matéria orgânica do solo. No presente trabalho verificou-se que no solo argiloso (LV) com teor médio de matéria orgânica (Tabela 1) a bananeira não respondeu à aplicação de $\mathrm{N}$ e, no LVA, que apresentou baixo teor de matéria orgânica, a bananeira respondeu positivamente à aplicação de $\mathrm{N}$ somente no $1^{\circ}$ ciclo, onde a produtividade da bananeira, geralmente, é menor em relação aos ciclos subsequentes; conclui-se, portanto, que para a recomendação de $\mathrm{N}$ para a bananeira 'Prata Anã' é essencial que além da produtividade esperada o teor de matéria orgânica do solo seja considerado.

Nos $2^{\circ}$ e $3^{\circ}$ ciclos da bananeira cultivada no LVA a aplicação de $\mathrm{N}$ reduziu a produção da bananeira e o modelo de regressão que melhor se ajustou foi o quadrático (Figura 1B e 1C). Este resultado pode ser devido ao material que se acumula no interior do bananal, a partir do $2^{\circ}$ ciclo, proveniente das folhas, pseudocaule e rizomas das plantas cortadas após a colheita do cacho de banana. Este material libera N, após sua mineralização, para o solo e este pode ser absorvido pela bananeira. Este N, somado ao proveniente da matéria orgânica do solo, provavelmente atendeu às necessidades da bananeira cultivada no LVA, nos $2^{\circ}$ e $3^{\circ}$ ciclos de produção e o aumento das doses de $\mathrm{N}$ pode ter provocado desequilíbrio nutricional na bananeira e queda na produção. Silva et al. (2003) também verificaram redução na produção nos $2^{\circ}$ e $3^{\circ}$ ciclos da bananeira 'Prata Anã' com o aumento das doses de N. Hoffmann et al. (2010) estimaram que a planta mãe da bananeira 'Prata Anã' restituiu, ao solo, $17 \mathrm{t} \mathrm{ha}^{-1}$ de matéria seca e aproximadamente $122 \mathrm{~kg} \mathrm{ha}^{-1} \mathrm{de} \mathrm{N}$.

Não houve efeitos significativos das doses de $\mathrm{N}$ aplicadas no LV sobre as variáveis de desenvolvimento vegetativo e de produção, nos dois ciclos de produção. A matéria orgânica do LV supriu, provavelmente, as necessidades de $\mathrm{N}$ da planta no $1^{\circ}$ ciclo já que o teor de matéria orgânica desse solo foi classificado como médio (Tabela 1) (Alvarez et al., 1999). A soma do $\mathrm{N}$ proveniente desta matéria orgânica com aquele proveniente da mineralização do material (folhas, pseudocaule e rizoma) que acumula no interior do bananal após a colheita do cacho de banana, pode ter suprido a bananeira no $2^{\circ}$ ciclo de produção. Avaliando doses de N na bananeira 'Terra', Borges et al. (2002b) também não obtiveram efeitos significativos na produção do $1^{\circ}$ ciclo visto que, para os autores, o solo no qual foi realizado o experimento apresentava alto teor de matéria orgânica $\left(43 \mathrm{~g} \mathrm{dm}^{-3}\right)$ e de $\mathrm{N}$ total $\left(1,8 \mathrm{~g} \mathrm{~kg}^{-1}\right)$ além de que foram aplicados $10 \mathrm{~L}$ de esterco de curral em todos os tratamentos, o que deve ter provido parte do $\mathrm{N}$ requerido pela bananeira. Sousa et al. (2004) também não encontraram, nos $1^{\circ}$ e $2^{\circ}$ ciclos da bananeira 'Grand Naine'e Santos et al. (2009) no 
$2^{\circ}$ ciclo da 'Prata Anã', resposta dessas bananeiras à aplicação de N.

A análise de variância mostrou que não houve diferenças entre os efeitos das fontes de $\mathrm{N}$ sobre as variáveis de desenvolvimento vegetativo e de produção da bananeira cultivadas nos LVA e LV. Alves et al. (2010) não constataram diferenças significativas entre os efeitos da ureia e nitrato de cálcio sobre as variáveis de produção da bananeira 'Grande Naine'; para os autores, o uso do nitrato de cálcio não é vantajoso haja vista que aumenta o custo de produção da bananeira em relação ao da ureia.

As doses de $\mathrm{N}$ aplicadas tanto no LVA quanto no LV, se ajustaram de forma linear com o teor de $\mathrm{N}$ nas folhas da bananeira (Tabela 2). Verificou-se que no LV, mesmo nos tratamentos nos quais não foi fornecido o $\mathrm{N}$ nos $1^{\circ}$ e $2^{\circ}$ ciclos de produção, o teor foliar deste nutriente apresentou-se dentro ou acima do nível de suficiência estabelecido por Silva et al. (2002) para 'Prata Anã', que é de 2,50-2,90 dag kg-1 (intercepto da regressão $=b_{0}$ ). Como o teor de $\mathrm{N}$ nas folhas da bananeira estava na região chamada adequação, em que o aumento do suprimento de determinado nutriente e de seu teor nos tecidos da planta não é acompanhado por aumentos expressivos no desenvolvimento e no crescimento, explica-se a falta de resposta da bananeira à aplicação de $\mathrm{N}$, fato que corrobora com o mencionado anteriormente, em que a matéria orgânica presente no LV supriu a bananeira de $\mathrm{N}$ no $1^{\circ}$ ciclo e a soma do $\mathrm{N}$ proveniente da matéria orgânica e da mineralização dos resíduos da bananeira (folhas, pseudocaule e rizoma) que permanecem no bananal após as colheitas, supriram a bananeira no $2^{\circ}$ ciclo. Tal raciocínio pode ser aplicado para os $2^{\circ}$ e $3^{\circ}$ ciclos da bananeira cultivada noLVA; no entanto, no $1^{\circ}$ ciclo da bananeira noLVA nos tratamentos em que o $\mathrm{N}$ não foi fornecido, o teor de $\mathrm{N}$ foliar apresentou-se abaixo do nível de suficiência (Tabela 2) o que favoreceu o aumento de produção da bananeira com a aplicação de N. Infere-se, portanto, que o $\mathrm{N}$ proveniente da matéria orgânica do LVA não foi suficiente para atender à demanda da bananeira no $1^{\circ}$ ciclo.

As aplicações de $\mathrm{N}$ nos LVA e LV no $1^{\circ}$ ciclo de produção não influenciaram os teores foliares de $\mathrm{K}, \mathrm{S}, \mathrm{Ca}$ e $\mathrm{Mg}$; as bananeiras cultivadas no LVA nos $2^{\circ}$ e $3^{\circ}$ ciclos e no LV nos $1^{\circ}$ e $2^{\circ}$ ciclos, apresentaram-se supridas de $\mathrm{N}$ mesmo quando este não foi fornecido; ao se aplicar $\mathrm{N}$, ocorreu desequilíbrio entre os nutrientes passível de ser observado nas regressões ajustadas entre os teores foliares de macronutrientes em função de doses de $\mathrm{N}$ aplicadas no solo (Tabela 3).

Ocorreram reduções lineares dos teores foliares de $\mathrm{Ca}$ e $\mathrm{Mg}$ com aumento das doses de $\mathrm{N}$ utilizando-se as diferentes fontes no $2^{\circ}$ ciclo da bananeira cultivada no LV, com exceção do nitrato de cálcio que não influenciou o teor foliar de $\mathrm{Ca}$; já o teor foliar de $\mathrm{S}$ foi reduzido de forma quadrática; a aplicação de $\mathrm{N}$ na forma de sulfato de amônio elevou linearmente o teor de $\mathrm{S}$ nas folhas, no $2^{\circ}$ ciclo da bananeira cultivada no LV e nos $2^{\circ}$ e $3^{\circ}$ ciclos da bananeira cultivada no LVA, em função do sulfato de amônio possuir $24 \%$ de $\mathrm{S}$.

No $2^{\circ}$ ciclo da bananeira cultivada no LVA as doses de $\mathrm{N}$ aplicadas utilizando-se as diferentes fontes, reduziram linearmente os teores foliares de K, S, Ca e Mg (Tabela 3). Silva et al. (2003) verificaram que o aumento das doses de $\mathrm{N}$ reduziu os teores de Ca nas folhas da bananeira 'Prata Anã' nos $2^{\circ}$ e $3^{\circ}$ ciclos e de $\mathrm{K}$ nos $2^{\circ}, 3^{\circ}$ e $4^{\circ}$ ciclos. Silva \& Carvalho (2005) verificaram que o teor foliar de $\mathrm{N}$ na bananeira 'Prata Anã' se correlacionou negativamente com o teor foliar de $\mathrm{K}$, em função da competição entre $\mathrm{K}^{+}$e $\mathrm{NH}_{4}^{+}$.

$\mathrm{O}$ teor foliar de $\mathrm{Ca}$ elevou-se linearmente com a aplicação do nitrato de cálcio como fonte de $\mathrm{N}$ nos $2^{\circ}$ e $3^{\circ}$ ciclos da bananeira cultivada no LVA; tal adubo é formado pela mistura de calcário calcítico ou dolomítico moído com nitrato de amônio apresentando, em sua composição, o Ca e o Mg.

O importante para a bananeira não são apenas os teores absolutos de $\mathrm{N}, \mathrm{K}, \mathrm{Ca}$ e $\mathrm{Mg}$ no solo mas principalmente o equilíbrio entre eles. A bananeira é uma planta sensível ao desequilíbrio nutricional; para elevar a produtividade da bananeira é importante manter no solo o equilíbrio entre os nutrientes evitando que ocorra consumo excessivo de um elemento induzindo deficiência de outro.

$\mathrm{Na}$ avaliação nutricional realizada em três bananais do norte de Minas Gerais, Silva (2004) verificou que as bananeiras com maior produção também apresentaram melhor equilíbrio nutricional, o que reforça a importância de se optar pelo fornecimento ou não de qualquer nutriente, unicamente com base no uso das ferramentas de diagnóstico: análise dos teores de todos os nutrientes no solo e nas folhas. A adubação sem diagnóstico pode apresentar, ainda, além de custo desnecessário, o agravante de prejudicar a produção.

O Mal-do-Panamá (Fusarium oxisporium F. sp Cubense) pode manifesta-se na bananeira 'Prata Anã' mesmo quando

Tabela 2. Regressões ajustadas entre o teor de $N$ nas fol has da bananeira 'Prata Anã' em função das doses de $N$ aplicadas no Latossolo Vermelho amarelo (LVA) e no Latossolo Vermelho (LV) com diferentes fontes

\begin{tabular}{|c|c|c|c|c|c|c|}
\hline \multirow{2}{*}{ Fontes de $\mathbf{N}$} & \multicolumn{6}{|c|}{ Ciclo de produção } \\
\hline & 10 & & 20 & & 3음 & \\
\hline $\begin{array}{l}\text { Sulfato de amônio } \\
\text { Uréia } \\
\text { Nitrato de amônio } \\
\text { Nitrato de cálcio }\end{array}$ & $\begin{array}{l}y=2,49+0,0011 x \\
y=2,49+0,0009 x \\
y=2,46+0,0010 x \\
y=2,48+0,0009 x\end{array}$ & $\begin{array}{l}\text { A. LVA - Latos } \\
\mathrm{R}^{2}=0,977 \\
\mathrm{R}^{2}=0,983 \\
\mathrm{R}^{2}=0,974 \\
\mathrm{R}^{2}=0,938\end{array}$ & $\begin{array}{l}\text { lo Vermelho amarelo } \\
\begin{array}{l}y=2,74+0,0006 x \\
y=2,75+0,0005 x \\
y=2,78+0,0006 x \\
y=2,75+0,0005 x\end{array}\end{array}$ & $\begin{array}{l}R^{2}=0,778 \\
R^{2}=0,735 \\
R^{2}=0,714 \\
R^{2}=0,738\end{array}$ & $\begin{array}{l}y=3,17+0,0007 x \\
y=3,07+0,0005 x \\
y=3,07+0,0004 x \\
y=3,30+0,0005 x\end{array}$ & $\begin{array}{l}R^{2}=0,784 \\
R^{2}=0,939 \\
R^{2}=0,874 \\
R^{2}=0,960\end{array}$ \\
\hline $\begin{array}{l}\text { Sulfato de amônio } \\
\text { Uréia } \\
\text { Nitrato de amônio } \\
\text { Nitrato de cálcio }\end{array}$ & $\begin{array}{l}y=2,62+0,0007 x \\
y=2,85+0,0008 x \\
y=2,68+0,0009 x \\
y=2,64+0,0007 x\end{array}$ & $\begin{aligned} & B . L V-L a \\
R^{2} & =0,957 \\
R^{2} & =0,844 \\
R^{2} & =0,762 \\
R^{2} & =0,7408\end{aligned}$ & $\begin{array}{l}\text { ssolo Vermelho } \\
y=2,82+0,0008 x \\
y=2,84+0,0007 x \\
y=2,94+0,0007 x \\
y=2,87+0,0003 x\end{array}$ & $\begin{array}{l}R^{2}=0,879 \\
R^{2}=0,857 \\
R^{2}=0,701 \\
R^{2}=0,800\end{array}$ & $\begin{array}{l}- \\
- \\
- \\
-\end{array}$ & \\
\hline
\end{tabular}


Tabela 3. Regressões ajustadas entre os teores de macronutrientes ( $\mathrm{K}, \mathrm{S}, \mathrm{Ca}$ e $\mathrm{M} \mathrm{g}$ ) foliares em função das doses de $\mathrm{N}$ aplicadas com diferentes fontes em bananeira 'Prata Anã'

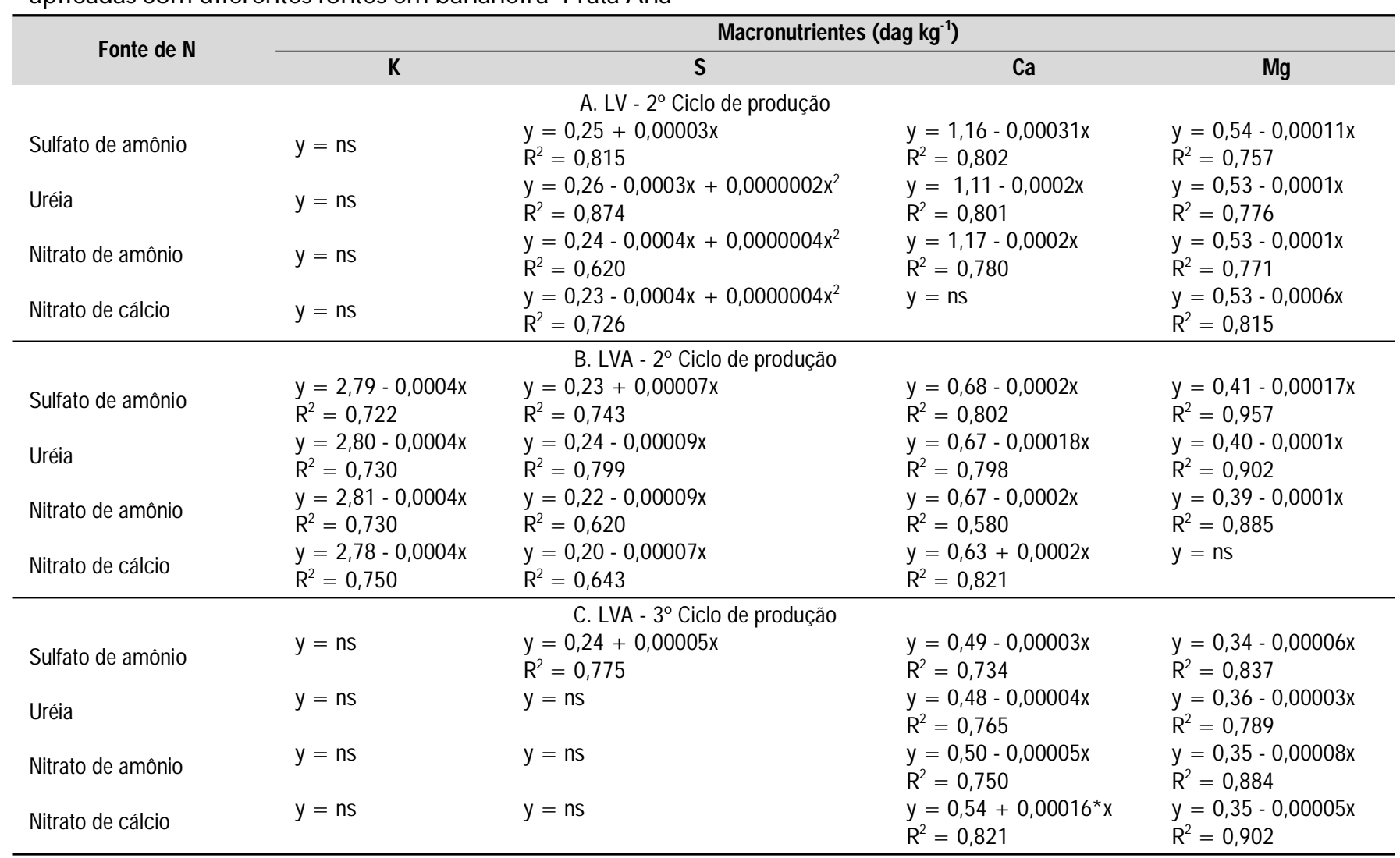

LV - Latossolo Vermelho; LVA - Latossolo Vermelho amarelo

são utilizadas mudas provenientes de cultura de tecidos, desde que o fungo encontre, no solo, condições favoráveis para sua manifestação, como o desequilíbrio entre os nutrientes $\mathrm{Ca}, \mathrm{Ke}$ $\mathrm{Mg}$ encontrado no LV, que apresentou relação entre esses nutrientes de 6,5: 0,3: 0,8 enquanto no LVA foi 2,0: 0,2: 0,4 (Tabela 1); apesar disto, a relação recomendada é 2,0: 0,3: 0,9, (Silva et al., 2008).

Com base nesses resultados verificou-se a necessidade de ampliar o número de pesquisas com a aplicação de $\mathrm{N}$ em bananeira 'Prata Anã' em diferentes tipos de solo com teores variados de matéria orgânica, em que os experimentos possam ser conduzidos no mínimo em três ciclos de produção. Os resultados dessas pesquisas serão importantes para que as recomendações de $\mathrm{N}$ para a bananeira possam ser baseadas na produtividade esperada e no teor de matéria orgânica do solo.

\section{ConclusõEs}

1. Não houve efeitos do N sobre as variáveis de desenvolvimento vegetativo e de produção, nos $1^{\circ}$ e $2^{\circ}$ ciclos da bananeira 'Prata Anã' cultivada no Latossolo Vermelho.

2. Para se obter a máxima eficiência física no $1^{\circ}$ ciclo da bananeira cultivada no Latossolo Vermelho amarelo, as doses de $\mathrm{N}$ foram: $521,471,410$ e $424 \mathrm{~kg} \mathrm{ha}^{-1}$ ano $^{-1}$, para o sulfato de amônio, nitrato de amônio, ureia e nitrato de cálcio, respectivamente.
3. Visando obter a máxima eficiência econômica no $1^{\circ}$ ciclo da bananeira cultivada no Latossolo Vermelho amarelo, as doses de $\mathrm{N}$ foram: 105, 204, 260 e $5 \mathrm{~kg} \mathrm{ha}^{-1}$, utilizando-se o sulfato de amônio, nitrato de amônio, ureia e nitrato de cálcio, respectivamente.

4. A aplicação de $\mathrm{N}$ reduziu a produção nos $2^{\circ}$ e $3^{\circ}$ ciclos da bananeira cultivada no Latossolo Vermelho amarelo.

5. A ureia foi mais eficiente para elevar a produção no $1^{\circ}$ ciclo da bananeira cultivada no Latosssolo Vermelho amarelo.

\section{AgRADECIMENTOS}

Ao Banco do Nordeste do Brasil, pelo financiamento do projeto de pesquisa.

\section{LITERATURA CITADA}

Alvarez V., V. H.; Novais, R. F de; Barros, N. F. de; Cantarutti, R. B.; Lopes, A. S. Interpretação dos resultados das análises de solos. In: Ribeiro, A. C.; Guimarães, P. T. G.; Alvarez, V., H. Recomendações para o uso de corretivos e fertilizantes em Minas Gerais. $5^{a}$ aproximação. Viçosa: CFSEMG 1999. p.25-32. Alves, M. S.; Coelho, E. F.; Paz, V. P. S; Andrade Neto, T. M. Crescimento e produtividade da bananeira cv. Grande Naine sob diferentes combinações de nitrato de cálcio e uréia. Revista Ceres, v.57, p.125-131, 2010. 
Borges, A. L.; Raij, B. van; Magalhães, A. F. de; Bernardi, A. C. de. Nutrição e adubação da bananeira irrigada. Cruz das Almas: Embrapa Mandioca e Fruticultura, 2002a. 8p. Circular técnica, 48

Borges, A. L.; Silva, T. O da; Caldas, R. C.; Almeida, I. E de. Adubação nitrogenada para bananeira-'terra'(Musa sp. AAB, subgrupo Terra). Revista Brasileira de Fruticultura, v.24, p.189-193, 2002b.

Brasil, E. C.; Oeiras, A. H. L; Menezes, J. E. A.; Veloso, C. A. C. Desenvolvimento e produção de frutos de bananeira em resposta à adubação nitrogenada e potássica. Pesquisa Agropecuária Brasileira, v.35, p.1-14, 2000.

EMBRAPA - Empresa Brasileira de Pesquisa Agropecuária. Centro Nacional de Pesquisa de Solos. Sistema brasileiro de classificação de solos. Brasília, Embrapa Produção de Informação; Rio de Janeiro: Embrapa Solos, 2006. 306p.

Hoffmann, R. B.; Oliveira, F. H. T. de; Souza, A. P.; Gheyi, H. R.; Souza Júnior, R. F. Acúmulo de matéria seca e de macronutrientes em cultivares de bananeira irrigada. Revista Brasileira de Fruticultura, v.32, p.268-275, 2010.

Maia, V. M.; Salomão, L. C. C.; Cantarutti, R. B.; Venegas, V. H. A.; Couto, F. A. A. Efeitos de doses de nitrogênio, fósforo e potássio sobre os componentes da produção e qualidade de banana 'Prata Anã' no distrito agroindustrial do Jaíba. Revista Brasileira de Fruticultura, v.25, p.319-322, 2003.

Malavolta, E.; Vitti, G. C.; Oliveira, A. S. Avaliação do estado nutricional das plantas: princípios e aplicações. 2.ed. Piracicaba: Potafos, 1997.319p.

Pinto, J. M.; Faria, C. M. B.; Silva, D. J.; Feitosa Filho, J. C. Doses de nitrogênio e potássio aplicados via fertirrigação em bananeira. Irriga, v.10, p.46-52, 2005.
Santos, V. P. dos; Fernandes, P. D.; Melo, A. S. de; Sobral, L. F.; Brito, M. E. B. Dantas, J. D. M.; Bonfim, L. V. Fertirrigação da bananeira cv. Prata Anã com N e K em um Argissolo Vermelho-Amarelo. Revista Brasileira de Fruticultura, v.31, p.567-573, 2009.

Silva, J. T. A. da. Avaliação nutricional da bananeira 'Prata Anã' (AAB) sob irrigação, no semi-árido do Norte de Minas Gerais. Lavras: UFLA, 2004. 129p. Tese Doutorado

Silva, J. T. A. da; Borges A. L. Solo, nutrição mineral e adubação da bananeira. Informe Agropecuário, v.29, p.23-34, 2008.

Silva, J. T. A. da; Borges, A. L.; Carvalho, J. G.; Damasceno, J. E. A. Adubação com potássio e nitrogênio em três ciclos de produção da bananeira Prata Anã. Revista Brasileira de Fruticultura, v.25, p.152-155, 2003.

Silva, J. T. A. da; Borges, A. L.; Dias, M. S. C.; Costa, E. L.; Prudêncio, J. M. Diagnóstico nutricional da bananeira PrataAnã para o Norte de Minas. Belo Horizonte: EPAMIG, 2002, 16p. Boletim Técnico, 70

Silva, J. T. A. da; Borges A. L., Malburg, J. L. Solos, adubação e nutrição da bananeira. Informe Agropecuário, v.20, p.2136, 1999.

Silva, J. T. A. da; Carvalho, J. G. Avaliação nutricional de bananeira Prata-Anã (AAB), sob irrigação no semi-árido do norte de Minas Gerais, pelo método Dris. Ciência e Agrotecnologia, v.29, p.731-739, 2005.

Sousa, V. F.; Veloso, M. E. C. da; Vasconcelos, L. F. L.; Ribeiro, V. Q.; Souza, V. A. B. de; D’Albuquerque Júnior, B. S. Nitrogênio e potássio via água de irrigação nas características de produção da bananeira 'Grand Naine'. Pesquisa Agropecuária Brasileira, v.39, p.865-869, 2004. 